\title{
A whole blood control for the Coulter Model S
}

\author{
L. O. MORGAN, W. G. JONES, J. FISHER, AND I. CAVILL
}

From the Department of Haematology, Nevill Hall Hospital, Abergavenny, Gwent, and the Department of Haematology, University Hospital of Wales, Cardiff, UK

SUMMARY The white cell count, red cell count, haemoglobin, and mean cell volume of a new preserved whole blood preparation used as a control material for the Coulter Model S were found to be stable for at least two months. This material provides a cheap and stable whole blood control which is now in routine use in 18 laboratories throughout Wales.

Quality control of automated blood counting systems is an essential part of the activity of a haematology laboratory. Effective quality control requires the inclusion of control samples in the routine test procedure (Brittin et al., 1969; Overton, 1971; Cavill and Jacobs, 1973) and analysis of the data by statistical methods. A simple and effective method for statistical analysis of control data has been developed (Cavill and Ricketts, 1974). Application of it has been limited by lack of a suitable control preparation. Existing commercial preparations are expensive and their supply is never assured.

A number of methods have been developed for stabilising blood by fixation. These have been reviewed by Lewis (1975), who concluded that fixed cells were more useful as standards for instrument calibration than for intralaboratory quality control. We have evaluated a new preparation containing fixed and partly fixed cells to see whether blood cells treated in this way could be used for the control of automated blood counters.

\section{Whole blood control}

A whole blood control should have a stable white and red cell count, mean cell volume (MCV), and haemoglobin and should mimic the behaviour of fresh human blood in the test method (Lewis, 1972a). Native white cells may be replaced in a stabilised whole blood preparation by either inert particles, fixed human red cells, or fixed avian cells (Lappin and Sanderson, 1970; Lewis, 1972b; Torlontano and Tata, 1972).

The whole blood preparation used in this study was prepared by a method developed at Nevill Hall Hospital and is now the subject of a patent applica-

Received for publication 11 July 1977 tion by the Department of Health and Social Security (DHSS). Red cells were obtained from either expired whole blood or red cell concentrates supplied by the Regional Blood Transfusion Service, Welsh Region, from material which was considered unsuitable for transfusion purposes. Whole blood was allowed to sediment at $4^{\circ} \mathrm{C}$, the plasma was removed, and the cells were treated with glutaraldehyde in a buffered isotonic solution. This treatment with glutaraldehyde was critical. The time and concentrations must be limited to stabilise the red cell membrane but not completely fix it. This allows the cells to be readily lysed for haemoglobinometry.

The final product was a mixture of human red blood cells and fixed avian cells suspended in a medium containing excess electrolyte, antibiotics, and human plasma. Each batch was stored for four weeks at $4-10^{\circ} \mathrm{C}$, during which time the red cells parameters became stable (Table 1). The haemo-

Table 1 Example of the 'maturation' of a batch of the whole blood preparation

\begin{tabular}{lllll}
\hline $\begin{array}{l}\text { 'Maturation } \\
\begin{array}{l}\text { time' } \\
\text { (days) }\end{array}\end{array}$ & $\begin{array}{l}W B C \\
\left(\times 10^{9} / l\right)\end{array}$ & $\begin{array}{l}R B C \\
\left(\times 10^{12} / l\right)\end{array}$ & $\begin{array}{l}H b \\
(g / d l)\end{array}$ & $\begin{array}{l}M C V \\
(f)\end{array}$ \\
\hline 0 & 8.8 & 3.97 & 11.9 & 104 \\
12 & 9.3 & 3.97 & 11.9 & 95 \\
18 & $9 \cdot 3$ & 3.98 & 11.9 & 90.5 \\
22 & $9 \cdot 3$ & 3.97 & 11.9 & 89.5 \\
25 & 8.9 & 3.96 & 12.0 & 89 \\
28 & 9.0 & 3.97 & 11.95 & 87 \\
32 & 9.2 & 3.99 & 11.9 & 85 \\
39 & 9.3 & 3.98 & 11.9 & 85 \\
46 & 9.2 & 3.96 & 12.0 & 84.6 \\
\hline
\end{tabular}

globin concentration of each batch was between 11.7 and $15.1 \mathrm{~g} / \mathrm{dl}$ with a red cell count of 3.91 to $5.03 \times 10^{12} / 1$ and white cell count of 5.0 to 14.2 $\times 10^{9} / 1$. The MCV was in the region of 77-86 $\mathrm{fl}$. The bulk material was dispensed as $15 \mathrm{ml}$ aliquots 
into glass or plastic screw-top containers using a peristaltic pump and continuous mixing (Ward et al., 1975). Dispensing was more easily done when the preparation had just been prepared.

The homogeneity of the dispensed aliquots was assessed in a total of 11 separate batches. Between 50 and 85 bottles, each containing $15 \mathrm{ml}$ of the whole blood control, were produced in each batch. A 1 in 5 sample of these bottles was taken, and the mean and variance for the haemoglobin $(\mathrm{Hb})$, red cell count (RBC), white cell count (WBC), and MCV were calculated from 10 replicate measurements for each bottle. The Coulter $\mathbf{S}$ was standardised using Coulter $4 \mathrm{C}$ at the beginning and end of each batch of 10 test analyses. Carry over was eliminated by priming the Coulter $S$ with a sample of each aliquot before the replicate measurements were made. An analysis of variance was carried out on the data from all of those analyses in which the $4 \mathrm{Cresults}$ for each parameter at both the beginning and the end of each bottle were within the following limits:

$\mathrm{Hb} \pm 0.1 \mathrm{~g} / \mathrm{dl} ; \mathrm{RBC} \pm 0.04 \times 10^{12} / \mathrm{l} ; \mathrm{MCV} \pm 1 \mathrm{fl} ;$ $\mathrm{WBC} \pm 0.2 \times 10^{9} / 1$.

The stability of the material was evaluated in seven separate batches. The means and variance for $\mathrm{Hb}, \mathrm{RBC}, \mathrm{MCV}$, and $\mathrm{WBC}$ in an aliquot of each batch were calculated from 10 replicate estimations on each day for about two months. Carry over was again eliminated by priming the Coulter $\mathbf{S}$ with a sample of each aliquot. $4 \mathrm{C}$ was also measured before and after each batch of 10 measurements. When either one or both of the $4 \mathrm{C}$ results for one of the four parameters fell outside the limits given above the test data were excluded from the subsequent analysis. Although this undoubtedly excluded a number of valid results it confined the observation to only those occasions when the accuracy of the apparatus was unquestionably constant.

Batches 2, 3, and 4 were prepared from expired whole blood and stored in glass containers, while batches 8 and 10 were also stored in glass but were prepared from packed red cells which were 16 days old. Packed cells were also used for the preparation of batches 9 and 11 but these were stored in plastic containers.

The robustness of the preparation was assessed by mixing aliquots in either glass or plastic containers each with or without glass beads. Aliquots in plastic containers were sent through the post on a 48-hour trip, being returned to the Nevill Hall laboratory for analysis. Further samples were transported quickly under controlled conditions via hospital transport to the University Hospital of Wales, Cardiff. These samples were then posted back to Nevill Hall for analysis after a 24-hour trip through the postal system. The 24- and 48-hour samples were analysed with a control aliquot which had been kept in the laboratory at $4-10^{\circ} \mathrm{C}$.

\section{Results}

The analysis of homogeneity of the dispensed preparation showed that the variation between aliquots was greater than within each aliquot. However, the biggest difference in the mean value of each parameter for each aliquot was in all but one instance less than $2 \%$ of the respective means of the batch. Indeed, the difference for the MCV was always less than $1 \mathrm{fl}$, the limit to which the Coulter $\mathrm{S}$ can measure. Although this level of variation was statistically significant it was not of practical importance.

The variation in the mean value for each parameter in the seven batches during the course of two months is shown in Table 2 and illustrated by a typical example (Batch 3) in the Figure. There was

Table 2 Variability of seven batches of whole blood control preparation

\begin{tabular}{|c|c|c|c|c|c|}
\hline & $\begin{array}{l}W B C \\
\left(\times 10^{\circ} / l\right)\end{array}$ & $\begin{array}{l}R B C \\
\left(\times 10^{12} / l\right)\end{array}$ & $\begin{array}{l}H b \\
(g / d l)\end{array}$ & $\begin{array}{l}M C V \\
(f)\end{array}$ & $\begin{array}{l}\text { Duration of } \\
\text { study (days) }\end{array}$ \\
\hline \multicolumn{6}{|l|}{ Batch 2} \\
\hline Mean & $5 \cdot 17$ & $4 \cdot 73$ & $14 \cdot 67$ & 86.0 & \multirow[t]{2}{*}{63} \\
\hline SD & $0 \cdot 14$ & 0.05 & 0.10 & 0.5 & \\
\hline \multicolumn{6}{|l|}{ Batch 3} \\
\hline Mean & $6 \cdot 08$ & $4 \cdot 10$ & $12 \cdot 67$ & $77 \cdot 6$ & \multirow[t]{2}{*}{63} \\
\hline SD & $0 \cdot 14$ & 0.03 & 0.14 & 0.8 & \\
\hline \multicolumn{6}{|l|}{ Batch 4} \\
\hline Mean & $14 \cdot 18$ & 3.90 & $11 \cdot 71$ & $77 \cdot 6$ & \multirow[t]{2}{*}{40} \\
\hline SD & 0.41 & 0.05 & 0.08 & 0.9 & \\
\hline \multicolumn{6}{|l|}{ Batch 8} \\
\hline Mean & $7 \cdot 47$ & $4 \cdot 29$ & $12 \cdot 82$ & $77 \cdot 6$ & \multirow[t]{2}{*}{61} \\
\hline SD & 0.26 & 0.01 & $0 \cdot 14$ & $1 \cdot 1$ & \\
\hline \multicolumn{6}{|l|}{ Batch 9} \\
\hline Mean & $7 \cdot 30$ & $4 \cdot 31$ & $12 \cdot 91$ & $77 \cdot 6$ & \multirow[t]{2}{*}{61} \\
\hline SD & $0 \cdot 24$ & 0.03 & 0.17 & $1 \cdot 0$ & \\
\hline \multicolumn{6}{|l|}{ Batch 10} \\
\hline Mean & $7 \cdot 50$ & $4 \cdot 36$ & $12 \cdot 81$ & $77 \cdot 3$ & \multirow[t]{2}{*}{61} \\
\hline SD & $0 \cdot 11$ & 0.04 & 0.13 & $1 \cdot 2$ & \\
\hline \multicolumn{6}{|l|}{ Batch 11} \\
\hline Mean & $7 \cdot 47$ & $4 \cdot 39$ & 12.90 & $77 \cdot 4$ & \multirow[t]{2}{*}{61} \\
\hline SD & 0.27 & 0.04 & $0 \cdot 17$ & $1 \cdot 4$ & \\
\hline
\end{tabular}

Mean $=$ mean of all samples.

SD $=$ SD of mean values for each aliquot.

no consistent correlation between the results for any of the parameters and the passage of time. Although there was a significantly greater variation between days than within each day for each parameter there was no consistently significant difference between the variance attributable to this material and the variance of the $4 \mathrm{C}$ preparation. There was no difference between the stability of the batches prepared from either outdated blood or packed cells, nor was there any difference between the batches stored in either glass or plastic containers.

The preparation appeared to be reasonably robust 

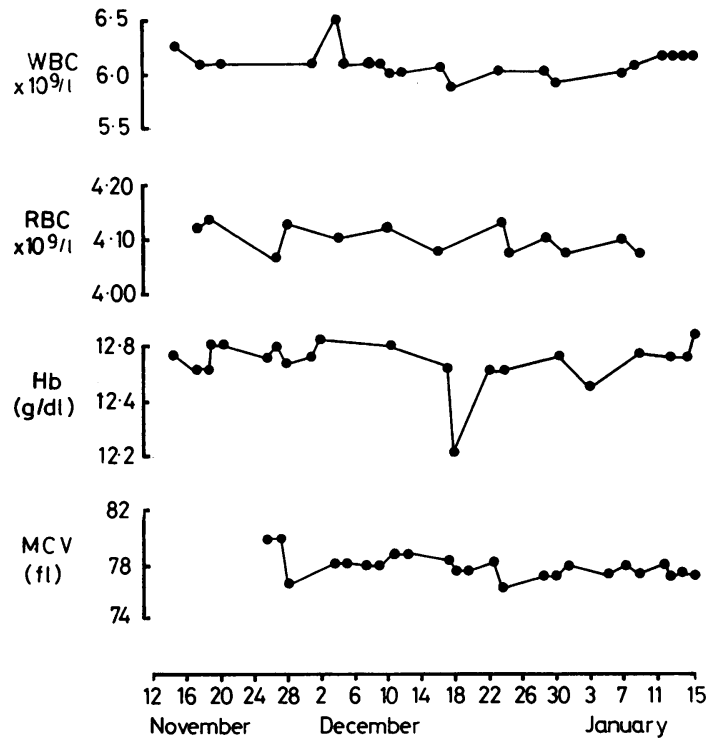

Figure Variation in white cell count $(W B C) \times 10^{\circ} / l$, red cell count $(R B C) \times 10^{12} / l$, haemoglobin concentration $(H b) \mathrm{g} / \mathrm{dl}$, and mean corpuscular volume (MCV) $\mathrm{fl}$ in a batch of new control material over a three-month period.

and the MCV rose by only 1-2 fl with prolonged continuous mixing, although the addition of glass beads produced a rapid rise in the MCV after two hours. The samples in the post for 48 hours also showed an increase in the MCV, but with a 24-hour journey the MCV remained constant. The $\mathrm{Hb}$, RBC, and WBC of the posted samples showed no significant difference compared with the samples kept at $4-10^{\circ} \mathrm{C}$ (Table 3$)$.

Table 3 Stability during 24-48 hours postal trip

\begin{tabular}{lllll}
\hline & $W B C$ & $R B C$ & $H b$ & $M C V$ \\
\hline Kept at 4-10 $10^{\circ} \mathrm{C}$ & $9 \cdot 2$ & $4 \cdot 01$ & $11 \cdot 9$ & 84 \\
24-hour postal trip & $9 \cdot 2$ & $4 \cdot 03$ & $11 \cdot 95$ & $83 \cdot 75$ \\
Kept at 4-10 $10^{\circ} \mathrm{C}$ & $8 \cdot 9$ & $4 \cdot 09$ & $12 \cdot 4$ & $84 \cdot 1$ \\
48-hour postal trip & $8 \cdot 9$ & $4 \cdot 08$ & $12 \cdot 4$ & 85 \\
\hline
\end{tabular}

\section{Discussion}

The statistical methods of intralaboratory quality control are well developed but their widespread application has been hampered by lack of a whole blood control material that is stable and inexpensive to buy or produce. We evaluated the DHSS formulation to see whether it could be produced in a homogenous bulk and supplied to a number of laboratories throughout Wales. The results show that a whole blood control prepared according to this new formulation is stable for at least two months when stored at $4-10^{\circ} \mathrm{C}$. Batch 3 was already two months' old when testing began, and it seems likely that this material can remain stable for more than four months.

One laboratory in Wales is now producing enough for itself and 17 others. It takes 16 hours a month to produce the 9 litres required by these laboratories. Either whole blood or packed cells remaining after the plasma has been removed seem equally suitable as a starting point for the preparation. It is easier to dispense the material as soon as it has been prepared and it must then be stored in the cold for about four weeks before the MCV becomes stable. Either glass or plastic containers may be used provided they are scrupulously cleaned and dried. During the 'maturation' process the red cells sediment and, owing to the method of stabilising the red cell membrane, the effect on the rheological properties of the cells makes resuspension slightly more difficult. Continuous but gentle mixing for 30 to 60 minutes is needed to resuspend the material evenly. Once the preparation has been mixed and is not required for further use it must be kept at $6^{\circ} \mathrm{C}$. Subsequent resuspension during the day requires only five minutes' mixing. Our experience has shown that prolonged mixing may cause the MCV to rise by 1-2 fl.

Stabilisation of the red cells with glutaraldehyde had no effect on the measurement of the haemoglobin concentration. Lysis of the red cells was complete within a few seconds, with no detectable turbidity, when the preparation was used in either the Coulter $\mathrm{S}$ or the manual method for estimating haemoglobin. The formalin-fixed avian cells used in the preparation remained intact in all the lysing agents used for measuring white blood cells. Direct measurement of the haematocrit of the preparation is not possible. The cells are suspended in excess electrolyte which makes them shrink and become rigid and they only regain their proper size when they are diluted in Isoton. The MCV which is measured by the Coulter $\mathrm{S}$ is, as with Coulter $4 \mathrm{C}$, related to these reconstituted cells.

On a number of occasions we observed significant simultaneous changes in the results from each batch which were of the same order and direction. For example, the marked fall in the haemoglobin concentration of Batch 3 on 18 December (Figure) was accompanied by similar changes in the results for Batches 2 and 4. Possibly this was the result of some random variation in each of the three control preparations that was not detected by the 1 in 5 sample which we had taken to assess homogeneity. Possibly also the variation in the Coulter $4 \mathrm{C}$ may have produced miscalibration on that particular 
day. In the absence of any independent yardstick we could not objectively distinguish between the two explanations. These results illustrate the difficulties that may result from accepting a standard for which there are no published data on its homogeneity or stability.

This formulation has been used to supply to each hospital in Wales enough of the control material to last one month. The material is prepared in bulk at one laboratory (Nevill Hall) and dispensed as 15-ml aliquots. For each batch a 1 in 10 sample of the bottles is taken to test its homogeneity. Each of the sampled bottles is assayed 10 times and the coefficient of variation of the mean values for $\mathrm{WBC}$, $\mathrm{RBC}, \mathrm{Hb}$, and MCV must be less than $1 \%$ if the batch is to be acceptable. The supply for each laboratory is dispatched either by post or with the assistance of Blood Transfusion Service delivery vans. Although 48 hours' exposure to postal handling was shown to cause a small rise in the MCV the brief journeys in the system have not had any detectable adverse effect on the material. Fifteen of the laboratories in the scheme use a Coulter $\mathrm{S}$ but three use a Hemalog 8. Although there is a difference in the red cell count and MCV obtained by these two groups of users the preparation is equally suitable to both.

The development of a similar scheme in other regions will depend on the circumstances of each laboratory or group or laboratories. In particular, the supply of time expired human blood or packed cells must depend on the policy of the regional blood transfusion service and other competing demands for blood. Our experience in Wales suggests that 20 units of packed cells per month is sufficient to supply the 18 hospitals. Collaboration between groups of laboratories, perhaps regionally organised, would be more efficient and would allow one centre to gain the necessary expertise in preparing and dispensing large volumes of the material.

Our results show that this new formulation can provide a haematology laboratory with a cheap and stable whole blood preparation for quality control. All the laboratories in Wales with automated equipment now have a routine supply of a stable whole blood preparation. Since the formulation to produce this control is now undergoing patent application by the DHSS any laboratory wishing to investigate the formulation may obtain the full method for its preparation free of charge by applying to Mr Rex Saunders, Scientific Adviser, Welsh
Office, Pearl House, Cardiff, South Wales. An example of the cost analysis of the preparation for an individual region is also available.

This study was carried out with the aid of a grant from the Welsh Office and was supported by the Blood Research Fund. We are indebted to Dr B. Bevan, of the Welsh Regional Blood Transfusion Service, for allowing us to use time-expired blood; to Dr J. N. Dearnaley and Professor A. Jacobs, in whose laboratories the work was carried out; and to Mr R. Saunders, Scientific Adviser, Welsh Office, for encouragement and advice. We would also like to thank Mrs I. Stacey for her help in typing the manuscript.

\section{References}

Brittin, G. M., Brecher, G., Johnson, C. A., and Elashoff, R. M. (1969). Stability of blood in commonly used anticoagulants: use of refrigerated blood for quality control of the Coulter Model S. American Journal of Clinical Pathology, 52, 690-694.

Cavill, I., and Jacobs, A. (1973). Quality control in haematology. Broadsheet 75, Association of Clinical Pathologists, London.

Cavill, I., and Ricketts, C. (1974). Automated quality control for the haematology laboratory. Journal of Clinical Pathology, 27, 757-759.

Lappin, T. R. J., and Sanderson, F. M. (1970). An artificial leucocyte control suspension. Journal of Clinical Pathology, 23, 65-67.

Lewis, S. M. (1972a). Developing a blood-cell standard. In Modern Concepts in Haematology, edited by $\mathrm{G}$. Izak and S. M. Lewis, p. 217. Academic Press, New York and London.

Lewis, S. M. (1972b). Cell counting-enumeration of blood cells and bacteria. In Biomedical Technology in Hospital Diagnosis, edited by A. T. Elder and D. W. Neill, p. 211. Pergamon Press, Oxford.

Lewis, S. M. (1975). Standards and reference preparation. In Quality Control in Haematology, edited by S. M. Lewis and J. F. Coster, p. 79. Academic Press, London.

Overton, K. L. (1971). A quality control program using the Coulter Counter Model S. American Journal of Medical Technology, 37, 235-239.

Torlontano, G., and Tata, A. (1972). Stable standard suspensions of white blood cells suitable for calibration and control of electronic counters. In Modern Concepts in Haematology, edited by G. Izak and S. M. Lewis, p. 230. Academic Press, New York and London.

Ward, P. G., Chappell, D. A., and Fox, J. G. C. (1975). Mixing and bottling unit for preparing biological fluids used in quality control. Laboratory Practice, 24, 577-583. 